\title{
CONTEMPORARY TECHNOLOGY SUPPORT FOR EDUCATION
}

\section{Teodor Savov, ${ }^{1}$ Valentina Terzieva, ${ }^{2}$ Katia Todorova, ${ }^{3}$ Petia Kademova-Katzarova ${ }^{4}$}

\begin{abstract}
The information and communication technologies (ICT) have penetrated into almost all areas of human life. They have a dual impact on education - increase learning efficiency and train students actively to use innovations. We assess this impact by examining teachers' experience with innovative tools in Bulgarian schools. In an anonymous online survey, we investigate their opinions on the issues related to technology integration in contemporary classrooms. The research shows that educators appreciate the benefits of technology implementation in the teaching-learning process, but they need a single structured system encompassing all technological resources and tools. This work proposes a conception for a smart classroom - an innovative learning environment that can establish and control suitable conditions for education as well as to impact the instructional process directly.
\end{abstract}

UDC Classification: 004.9; DOI: http://dx.doi.org/10.12955/cbup.v5.1029

Keywords: ICT, smart classroom, personalization, Internet of things (IoT) , technology-enhanced learning

\section{Introduction}

Recently the information and communication technologies (ICT) have become omnipresent in the whole society, and the educational area is not an exception. The traditional classroom becomes rich of technology to meet the expectations of digital age. Although it provides many facilities, the usage of technology as a tool to boost students learning is still evolving. So as to get know to what extent this practice has penetrated into Bulgarian schools, we conducted an online survey among innovative teachers. It is designed to explore their general perceptions and attitude to technology in education. The main goal is to gain a better understanding of how teachers implement ICT in their work, what are the important aspects and which are the most used tools and services. Data from our study shows that teachers still have a dual attitude to technology - they recognize its value, but they still need more qualification and help when it comes to using it in meaningful and engaging ways for students. Most of the teachers are ready to use ICT tools in classrooms. However, there are not enough appropriate applications integrated into a single structured system. Furthermore, respondents outline contemporary usage trends as well as the forward-looking technology applications to smarten up the teachinglearning process. To generalize, teachers require not only structural but functional enhancement of the learning space. They need an engaging learning environment, satisfying the different educational needs and interests of learners, fostering collaboration and interaction between students and teachers as well as supporting multiple ways to share knowledge. Traditional classroom transformed to smart one, i.e. designed with build internet of things (IoT) integrated into a smart educational system can fulfill such educational needs.

\section{Teachers' Opinions}

According to the survey, only $40 \%$ of the respondents have a learning management system in their schools. The use of ICT in support of educational process has versatile effects for both teachers and students. It enables the creation of a dynamic environment that allows students to express both their skills and competencies and to acquire new knowledge. In such an environment various tools for personalization of learning process according to students' preferences and needs can be used.

Relay on their experience, respondents point out some of the most significant advantages of using technology-enhanced learning. Fig. 1 depicts a detailed diagram of their answers. During their pedagogical activities, most of the teachers (89\%) recognize increased interest and activity of learners, which is directly related to technology-based resources that add value to traditional training by multisensory elements. The method contributes to a more comprehensive perception of the material (imperceptibly learning - 74\%), and the result is increased effectiveness (67\%). More attractive learning resources and access to extra information increase the motivation, the pace of work and the degree of acquiring of knowledge. Last but not least, students acquire computer literacy (59\%) that

\footnotetext{
${ }^{1}$ Bulgarian Academy of Sciences, Sofia, Bulgaria, teodor_savov@isdip.bas.bg

${ }^{2}$ Bulgarian Academy of Sciences, Sofia, Bulgaria, valia@isdip.bas.bg

${ }^{3}$ Bulgarian Academy of Sciences, Sofia, Bulgaria, katia@isdip.bas.bg

${ }^{4}$ Institute of Information and Communication Technologies - Bulgarian Academy of Sciences, Sofia, Bulgaria, petia@isdip.bas.bg
} 
stimulates independent learning according to $53 \%$ of respondents. Technology is a valuable tool for teachers - it enables new instruction forms and methods (72\%), and it helps especially adaptation and personalization upon presentation of the material as well as immediate feedback (61\%). As the results of the survey show an excellent effect of the technology-enhanced learning, we come to the decision to develop a concept of a smart classroom.

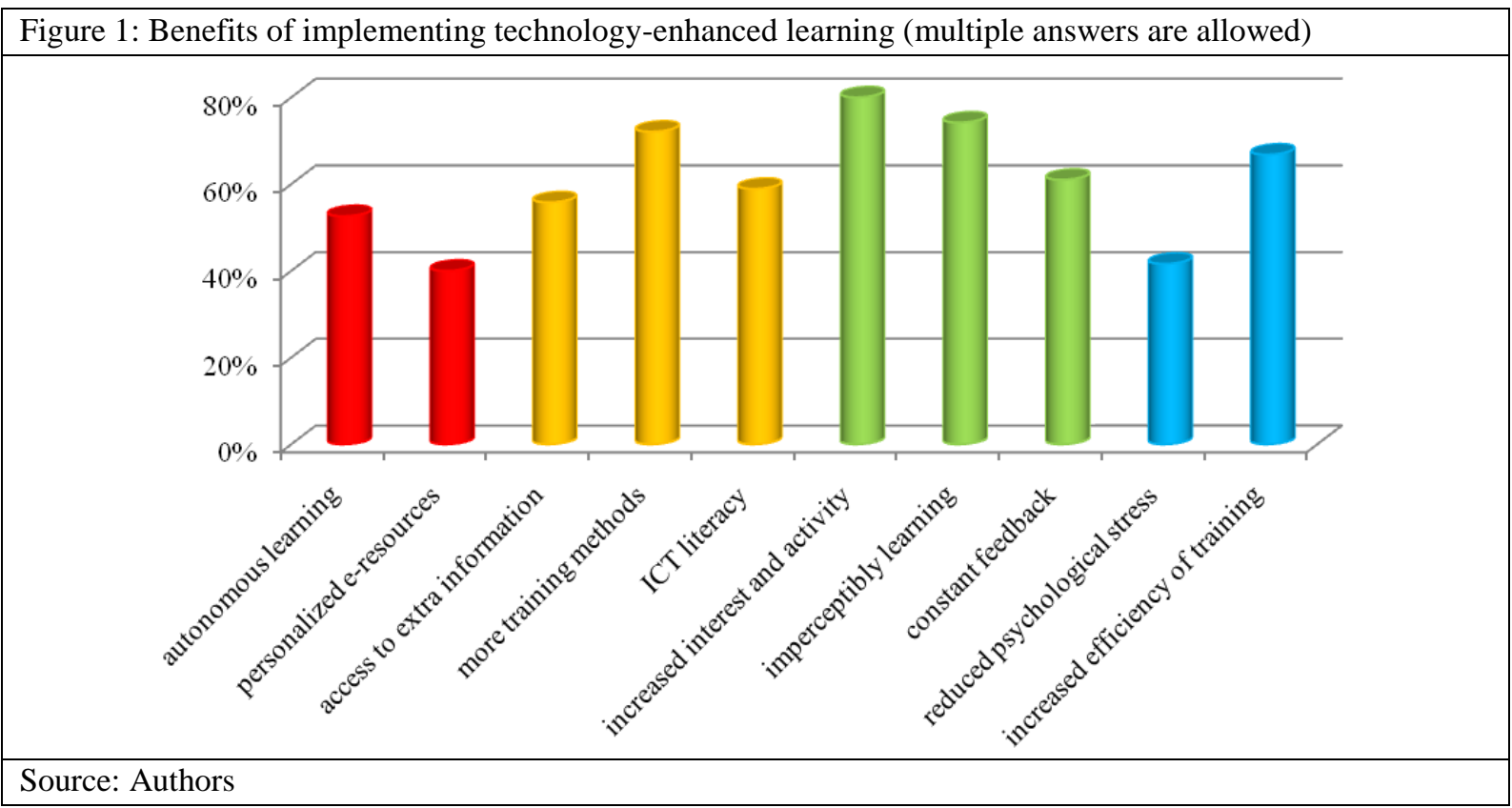

\section{Conception of Smart Classroom}

The widespread opinion is that smart classroom should involve an integration of technology within the learning space. Many researchers stress their attention also on the need of methodological paradigm shift - providing a modern and efficient education services by combining innovative pedagogy and technological teaching tools. Gligorić et al. (2012) present smart classroom concept and methodology for monitoring student's attention. Slotta et al. (2013) work out a pedagogical model (Knowledge Community and Inquiry) and describe an interaction between people, materials, tools, and environments. Rehman et al. (2008) show the great importance of RFID system in an educational environment as a way for increasing physical security of students and teachers. Temkar et al. (2016) study IoT for improving the learning process. Uskov et al. (2016) make a classification of a wide range of applications and software for smart classroom and university environment which could be applicable for the current conceptual model of a smart classroom. Bogart and Wichadee (2016) do research among 40 students concerning smart classroom technologies and take into account their opinions and recommendations. Lane and Finsel (2014) research the usage of Big Data in smart colleges and universities. Their work offers a technique how these data can be collected, analyzed and used for achieving better results.

The paper outlines authors' concept of a smart classroom - a learning space that better fits the learning needs and expectations of the digital generation. The focus is both on the technology that creates conditions for the effective learning process and innovative technology-enhanced pedagogy. Therefore, as Terzieva et al. (2016) write, the smart classroom should provide basic and functional smartness. The first one is responsible for specifying and controlling microclimate parameters of the room that have an indirect influence on the learning process and ensure learning comfort. Usually, monitoring and control of the microclimate are performed by an air-conditioning system or smart window that open at certain times, depending on the schedule of room usage. Functional smartness concerns provision of appropriate tools for a smart teaching-learning process. A smart classroom is intended to employ technologies that directly impact the methodology, design, structure, and implementation of the teaching process. During the lesson, sensors monitor student's engagement and their activity parameters (response time, the correctness of answers, etc.) and to provide teachers with real-time feedback and information. Furthermore, such information allows teachers to get deep inside 
of student's knowledge acquisition and thus to adapt and personalize the process of teaching for every student according to individual characteristics if needed.

The main purpose of the smart classroom is to enable a smart educational process - from management of the teaching process, through the workspaces for teachers and students to knowledge delivering and testing. Smartness implies pedagogical changes - teaching practices evolve; various innovative teaching strategies that require new roles of teachers and students emerge; new types of learning content and resources appear; extra learning opportunities are offered. Also, smart functionality provides an opportunity for personalization basing on automatic tracking of student's attendance and recording individual progress. This information helps teachers' decisions about appropriate interventions in supporting individual needs or overcoming encountered problems and difficulties. The data, related to the teaching-learning process, are stored in a centralized repository as a part of web based smart learning system that serves all the education-related issues.

\section{Structural Model of Smart Classroom}

This model is a conception for smart learning environment build by using most of the modern technical achievements in fields of IoT, wireless sensors networks, Big Data, etc. according to educational requirements and student's needs. The project is open for implementation of new features and different technologies not only for responding of changeable educational necessities but also for adapting a system to a broad circle of users. Bogart and Wichadee (2016) write that term "smart classroom" can be misleading because by itself the classroom is not smart in any sense of the word, nor are students who are taught in a smart classroom necessarily going to become smart by learning lessons in one.

A structure of this conceptual model consists of five operational modules in which specialized software operates and controls all physical elements and devices (hardware) - refer to Fig 2.

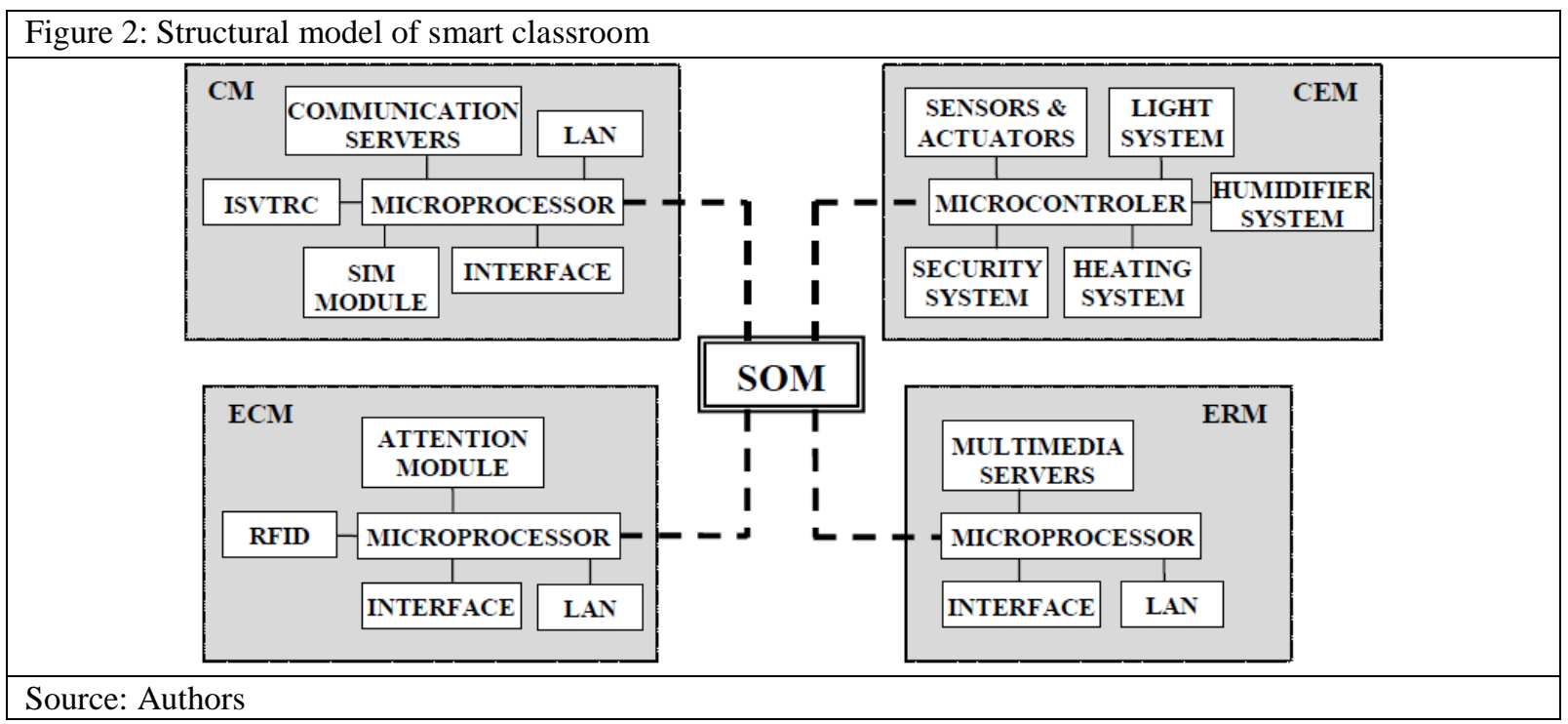

\section{Classroom environment module (CEM)}

This module is responsible for supporting and providing normal environmental conditions in the learning process. There are a variety of sensors and actuators that measure different environmental parameters as temperature, motion or presence, humidity, dust, oxygen level, noise level, lightening, water dispenser shortage, recycle bin fullness, security system, etc. According to these parameters, a microcontroller runs and controls central heating system, light system, fresh air flow, cleaning schedule and sending service messages to school staff. This microcontroller is connected through Bluetooth to the central microcontroller, which is a part of System operation module (SOM). CEM is individual for each classroom and could be set up according to studying material or student's needs. The system could be adapted to work for students with special needs.

System operation module (SOM)

This unit coordinates all modules and supports the whole system in working order. It maintains connections with other modules constantly and provides coordination between different subsystems. 
That part is the brain of the entire system. This module processes all the data concerning learning process and system functionality. It provides a broad range of settings and different profiles for each user. SOM may coordinate more than one classroom. For that reason, classrooms with same characteristics and parameters are combined and managed by one module.

Educational resource module (ERM)

The educational resource module is the most powerful and provides a broad range of educational services. There are several multimedia servers with various data covering all study materials electronic textbooks, manuals, movies, audio, learning applications and specific learning software. This module has an interactive system for creating lessons and task for students. The application helps teachers to prepare their lessons and organize classes by using all multimedia devices and smart classroom resources. Slotta et al. (2013) explain that such systems could simulate different learning environments (as rainforests, war scenes, manufacture installation, etc.) and include all students in researching and observing activities. Students also have a right to use this module through a special account and student's profile that allows them to access all learning resources in the classroom or do their homework remotely at home due to the Communication module and secure Internet connection. This module is connected to other modules by SOM and could use their resources for providing better educational process. ERM is common for the whole school. It could be utilized for all classrooms because it contains the full complex of studying materials for students of different course's groups.

Communication module $(\mathrm{CM})$

The communication module is a combination of various communication applications and services. There are an email server and client software, instant messages applications, Internet connectivity, mobile connectivity and interactive system for voice, text and remote control system for classroom activities (ISVTRC). An important part of the learning process for teacher and students is ISVTRC. This system connects all monitors and peripherals like a touch pad, headphones, camera, microphone mouse and keyboard put on every student's desk, multimedia smart board, projector and teacher's personal computer. Different learning styles can be accepted using a multimedia smart board. Temkar et al. (2016) indicate that learners can learn by touching the board and visual learners can help themselves by observing the teaching on the board. Uskov et al. (2016) classify different software that allows the teacher to communicate via text or voice messages to students and observe student's work on their desktops. All students' desk connections are LAN based. The teacher can be in touch with all students in class activities by this system. He/she could send a text or voice messages in real time or monitor student's desktop by remote control. The module also provides Broadband Internet access to all users. A SIM module connected to the system can send short text messages or make a phone call to students or their parents in real time.

Evaluation and control module (ECM)

A module carries out various exams and tests for students. There is an electronic diary for each student and detailed information about student's work and achievements. Parents have a chance to access this electronic diary and be notified about their children's grades. The system could be set up to send instant messages or SMS to parents concerning the behavior, grades or absences of their kids. There are a website and mobile application (Android and iOS) with detailed information for children achievements. Lane and Finsel (2014) conclude that performance of a student in a given semester was not known until course grades were reported and GPA calculated at the end of the semester. While it is possible to track student activity on an almost daily basis and provide interventions in the middle of the semester with the desire of supporting the success of the student.

The vital part of this module is a subsystem for measuring student attention. While active learning activities run, the teacher has an opportunity to monitor each student's care and take measures for increasing student's attention. This system constantly sends data to SOM, which can change some environmental parameters automatically by CEM to increase students' attention and concentration. The system evaluates individual student behavior and behavior of entire group by observing the level of noise, student's movements and analyzing facial expression. Gligorić et al. (2012) write that fidgeting and noise are two most common ways of expressing the lack of interest. Noise sensors, PIR sensors RFID reader, and camera are installed on every student's desk. RFID reader allows students to identify themselves and to log in the system by special RFID ID card. Rehman et al. (2008) point out that this 
card could be used for access to classroom, school library, sports facilities, and canteen. Although that allows different groups of students to use one classroom, it is better every group (class) to have an individual classroom. That way in each classroom could have access only student from the specific group. This module manages several databases for system logging and collecting student's grades and other personal data. ECM is specific software for each classroom.

The system is built for the following groups of users:

- Students (limited privileges and rights to access ad hoc applications, devices, and learning resources; rights for setting up a personal profile)

- Teachers (wide privileges and rights to use different applications, upload, remove and create new educational resources)

- Parents (monitoring and communication functions; wide possibilities to contact with students and teachers through the communication module)

- School staff and technical maintenance (specific tasks and duties concerning service and system's maintenance)

- Admin (administrative function).

\section{Conclusion}

The proposed concept of a smart classroom has many advantages - it presents learning spaces that can be easily adapted to meet a variety of teaching approaches and learning preferences. In fact, it is an active learning environment that can improve students' engagement by facilitating their focus and concentration. It meets students' curiosity and supports a better understanding of matter by enabling interactive teaching with multimedia learning resources and access to extra information beyond the syllabus. Also, there are technical facilities for recording lectures and digital handouts which are a benefit for absentees and distant students. Smart classroom empowers teachers with the necessary technology tools for managing and providing smart teaching process - real-time feedback, comprehensive reporting and various analyses. It can support different tasks for different groups of learners and provide real-time feedback, assessment, and directions. Furthermore, communication module enables discussions with colleagues, tutors, researchers, experts, etc. as well as the acquisition of relevant information of live events beyond the scope of the textbook. As a disadvantage of the smart classroom, it can be pointed out the need of additional qualification of teachers as well as the maintenance and regular updating of the system components.

\section{Acknowledgements}

Our work is a part of project "Conceptual Modeling and Simulation of Internet of Things Ecosystems" (KoSMEIN) financed by Bulgarian National Science Fund. We express our deep sense of gratitude to our grant and all participants in this project.

\section{References}

Gligorić, N., Uzelac, A., Krco, S. (2012). Smart classroom: real-time feedback on lecture quality (PERCOM Workshops). pp. 391-394. IEEE, Lugano, Switzerland doi:10.1109/PerComW.2012.6197517

Slotta, J., Tissenbaum, M., Lui, M. (2013). Orchestrating of complex inquiry: three roles for learning analytics in a smart classroom infrastructure. (LAK'13), pp. 270-274. ACM, New York, NY, USA doi:10.1145/2460296.2460352

Lane, J., Finsel, A. (2014). Fostering smarter colleges and universities data, big data, and analytics. (State University of New York Press).

Uskov, V.L., Bakken, J.P., Pandey, A., Singh U. Yalamanachili M., Penumatsa A. (2016). Smart university Taxonomy: Features, Components, Systems. Smart Education and e-Learning. Smart Innovation, Systems and Technologies, vol. 59, pp 3-14. Springer ISBN 978-3-319-39690-3

Rehman A., Abbasi A. Z., Shaikh Z. A. (2008). Building a smart university using RFID technology. (International conference on computer science and software engineering).

Temkar R., Gupte M., Kalgaonkar S. (2016). Internet of things for smart classrooms. (International research journal of engineering and technology).

Bogart W., Wichadee S. (2016). Student' perceived effectiveness of educational technologies and motivation in smart classroom. TEM Journal. Volume 5, Issue 4 pp566-574 doi: 10.18421/TEM54-22

Terzieva, V., Todorova, K., Kademova-Katzarova, P. (2016) IoT in Schools: Smart Classroom, Personalized Environment Proceedings of the International Conference BdKCSE`2016, Sofia, pp. 89-99. 